\title{
Tissue-Engineered Products for Skin Regenerative Medicine
}

\section{Yoshimitsu Kuroyanagi}

R \& D Center Skin Regenerative Medicine, Technosurg Ltd., Sagamihara, Japan

Email: drs.yoshi@technosurg.co.jp

How to cite this paper: Kuroyanagi, Y. (2016) Tissue-Engineered Products for Skin Regenerative Medicine. Open Journal of Regenerative Medicine, 5, 61-84. http://dx.doi.org/10.4236/ojrm.2016.53006

Received: July 27, 2016

Accepted: September 18, 2016

Published: September 21, 2016

Copyright $\odot 2016$ by author and Scientific Research Publishing Inc. This work is licensed under the Creative Commons Attribution International License (CC BY 4.0).

http://creativecommons.org/licenses/by/4.0/

(c) (i) Open Access

\begin{abstract}
In a general wound healing process, foreign bodies and tissue detritus have to be broken down and then a new tissue is produced. However, the new tissue formation sometimes fails to proceed under the impaired conditions such as burn injury and intractable skin ulcer. A major obstruction to wound healing is infection. Another obstruction to wound healing is deficiency of growth factors. The endogenous levels of growth factors are reduced in some chronic wounds. To improve these wound conditions, researchers have been trying to create several types of artificial skins. The tissue-engineered products include three prime constituents, i.e., cells, growth factors, and materials. In this review, the practical design of tissue-engineered products for skin regenerative medicine is introduced. The first design makes it possible to release silver sulfadiazine (AgSD) from a wound dressing. The second design makes it possible to release Epidermal Growth Factor (EGF) from a wound dressing or a skin care product composed of hyaluronic acid spongy sheet containing bioactive ingredients. The third design makes it possible to release several types of growth factors from allogeneic fibroblasts within cultured dermal substitute. This tissue-engineered product is prepared by seeding allogeneic fibroblasts into a collagen and hyaluronic acid spongy sheet. Although allogeneic cells are rejected gradually in immune system, they are able to release some types of growth factors, thereby regenerating a damaged tissue. The clinical study demonstrates that these tissue-engineered products are promising for the treatment of burn injury and intractable skin ulcer.
\end{abstract}

\section{Keywords}

Tissue Engineering, Wound Dressing, Cultured Skin Substitute, Antimicrobial Agent, Growth Factor

\section{Introduction}

Our skin is composed of epidermis, dermis, and subcutis. It not only provides a barrier 
against harmful microorganisms, but is also essential for maintaining the body's fluid balance. Many different types of injury result in damage to the skin. The body is usually capable of closing these wounds and restoring the original functions of its protective covering. This process involves a variety of repair mechanisms. The general wound healing process is characterized by an orderly sequence of events. Tissue response to injury has been divided into three overlapping phases: inflammation, proliferation, and remodeling [1]. Various growth factors released from platelet stimulate the orderly migration of cells into the wound site. Macrophages also serve as an important source of growth factors that are essential for wound healing. During the proliferation phase, endothelial cells and fibroblasts are predominant cell types. The neovascularization process requires migration and proliferation of endothelial cells in order to form new functioning blood vessels. The granulation process requires migration and proliferation of fibroblasts. Fibroblasts release stimulatory and inhibitory growth factors, thereby regulating the synthesis and deposition of extra cellular matrix components. The epithelialization process requires migration, proliferation, and differentiation of keratinocytes found in the residual epidermis and skin appendages. This process is facilitated by growth factors secreted from fibroblasts and keratinocytes.

Normal acute wounds successfully proceed through coordinated and predictable series of cellular and biochemical events. However, some chronic wounds fail to proceed through an orderly and timely healing process, because certain pathophysiologic conditions and metabolic factors involved in these chronic wounds can alter cellular functions and also reduce an ability to prevent infection. These wounds result from deficiency of growth factors. The critical issue is to improve the chronic wound conditions. Thus, it may be possible to facilitate a wound healing response in chronic wounds by adding exogenous growth factors. A variety of cytokines including platelet derived growth factor (PDGF), basic fibroblast growth factor (bFGF), epidermal growth factor (EGF), vascular endothelial growth factor (VEGF), and hepatocyte growth factor (HGF) have been applied to chronic wounds in clinical studies [2]-[6]. Another strategy is to develop several types of antibacterial agent-incorporating wound dressings, growth factor-incorporating wound dressings, and fibroblast and/or keratinocytes-incorporating skin substitutes. These cells are capable of releasing several types of growth factors that are essential for wound healing to proceed successfully. The creation of artificial skin needs the basic knowledge on wound healing, especially the functions of cells and growth factors in wound healing process.

\section{General Design of Wound Dressings}

\subsection{Design of Conventional Wound Dressing}

To introduce the concept of new wound dressings, the general considerations of wound healing should be discussed. The primary function of wound dressing is to promote rapid tissue repair by providing a moist healing environment for the wound and also providing a barrier to the external environment. Since George Winter's discovery [7] of the benefits of moist wound healing in the 1960's, there has been an explosion in the 
development of occlusive membrane-type wound dressings. This principle is based on general considerations of wound healing, depending on the functions of neutrophils and macrophages in the early stages after injury. Commercially available wound dressings consisting of a polyurethane membrane are capable of minimizing evaporative water loss from the wound and preventing bacterial invasion, and thus are useful in the management of partial-thickness wounds such as donor site wounds and superficial second-degree burns. However, they fail to success the treatment of deep second-degree and third-degree burns.

Early tangential excision followed by autologous split-thickness skin grafting has been a gold standard procedure [8]-[10]. In the management of a massive burn injury, however, temporary wound dressings have been widely used to cover the debrided wound until second and third autologous split-thickness skin grafts are available. Prompt wound coverage with an excellent material is a life-saving procedure. The cadaver skin graft is employed as an excellent treatment for burn wounds. As a replacement for cadaver skin graft, several types of covering products have been used. The ideal structure of a wound dressing consists of an outer membrane and an inner threedimensional base material (matrix) of fabric or sponge. The outer membrane prevents loss of body fluids, controls evaporation of water, and protects the wound from bacterial invasion, whereas the inner matrix encourages its adherence on the wound area by tissue growth into the matrix. One of these ideal wound dressings was developed by Woodroof [11], which was composed of a silicone membrane bonded to a nylon fabric with a small amount of collagen peptide. The silicone membrane functions as a barrier, controlling evaporative water loss and preventing bacterial invasion, whereas the nylon fabric provides a rough surface that promotes its adherence to the wound area. Another ideal wound dressing was developed by Yannas and Burke [12] [13], which was a biosynthetic bilaminar wound dressing composed of a silicone membrane and a collagen-glycosaminoglycans spongy matrix. In addition, same type of wound dressing composed of a silicone membrane and a collagen spongy matrix was developed [14] [15].

\subsection{Design of Wound Dressing Containing Antimicrobial Agent}

A major obstruction to wound healing is infection. If wound contamination occurs, the inflammatory phase may persist and interfere with the next phases of wound healing. Non-medicated wound dressings are used for partial-thickness wounds free from a risk of infection, because the synergistic functions of neutrophils and macrophages are able to facilitate the inherent wound healing capability. For infected wounds, however, an antimicrobial agent is necessary, because the beneficial effect of neutrophils and macrophages is limited. The management of severe burns and ulcers needs to suppress bacterial growth, particularly when eschar and damaged tissue are present.

In the successful wound management of deep second-degree burns, third-degree burns, and skin ulcers, drainage of exudate must be taken into account, because excess amount of exudate buildup beneath the wound dressing is more prone to infection. The 
wound dressing should have slits or pores to prevent excess amount of exudate buildup, but its integrity must be maintained to prevent external bacterial invasion. To resolve these conflicting requirements, the concept of the drug delivery system has been introduced in the field of wound dressing [16]-[21]. Antimicrobial agent-incorporating wound dressings with slits or pores have proven effective in preventing bacterial invasion by releasing antimicrobial agents. These wound dressings are designed to provide the following functions: 1) inhibition of body fluid loss, 2) promotion of drainage and prevention of exudate buildup, 3) protection from external contamination, 4) sufficient bactericidal effect to inhibit infection, 5) preparation of optimum wound bed for autografting.

\subsection{Design of Wound Dressing Containing Biological Agent}

To develop more efficacious methods of wound management, the use of biological materials and biologically active substances has been discussed. Hyaluronic acid (HA) is considered as one of the most useful biomaterials for wound healing. There are two possibilities for the role of HA in cell motility. First, it may facilitate adhesion-disadhesion between the cell membrane and the extra-cellular substratum during cell movement. Second, HA can become an extremely hydrated molecular structure, and thereby result in tissue swelling that creates additional space between collagen and cells, thus facilitating migration of more cells into this area. In addition, HA is a promising biodegradable material, since it does not substantially express immunogenicity. In additon to biological materials, the application of biologically active substances has been considered as a new therapy. Various growth factors, such as EGF and bFGF have been applied as new therapies for the treatment of skin ulcers. The next generation of wound dressing needs to promote wound healing pharmaceutically by using biologically active substances.

\section{Development of Wound Dressing Containing Antimicrobial Agent}

AgSD-incorporating wound dressing was developed [20] [21]. This wound dressing is composed of AgSD-incorporating polyurethane membrane, laminated with a non-woven fabric as a backing. This wound dressing is designed to have $5 \mathrm{~mm}$ slits separated 5 $\mathrm{mm}$ from each other to promote drainage of exudate in clinical application Figure 1. The antimicrobial properties of this wound dressing were studied on agar plates seeded with $P$. aeruginosa Figure 2. Pseudomonas aeruginosa were seeded on agar plates on which AgSD-incorporating wound dressing was placed for 3 days at $37^{\circ} \mathrm{C}$, and then the bacteria were counted. The wound dressing containing AgSD at $50 \mu \mathrm{g} / \mathrm{cm}^{2}$ was effective in suppressing bacterial growth.

On the basis of excellent results in the fundamental study, this AgSD-incorprating wound dressing was evaluated in 150 clinical cases. The polyurethane membrane side of the dressing was placed on the wound surface, over which conventional gauze dressing was applied. For deep second-degree burns, the wound dressing was exchanged at 


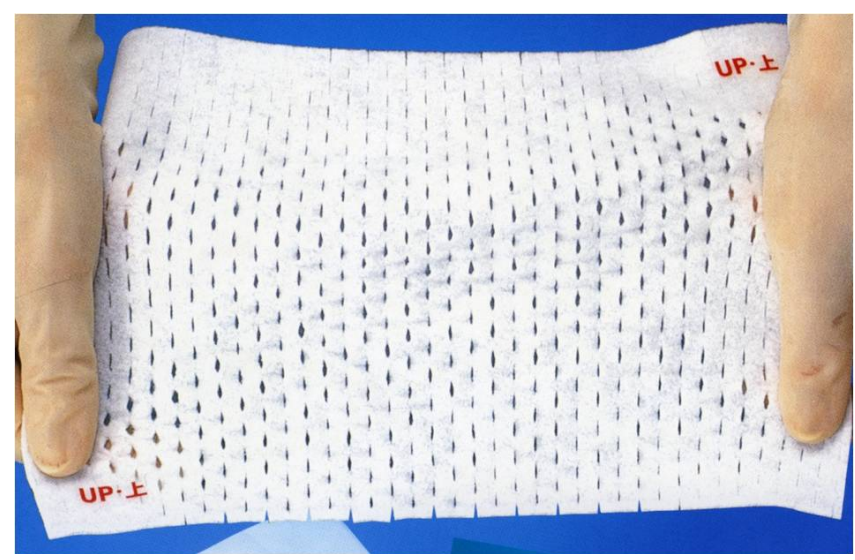

Figure 1. Wound dressing is stretched to open the slit structure, be capable of promoting drainage and preventing excess accumulation of exudate beneath the wound dressing.

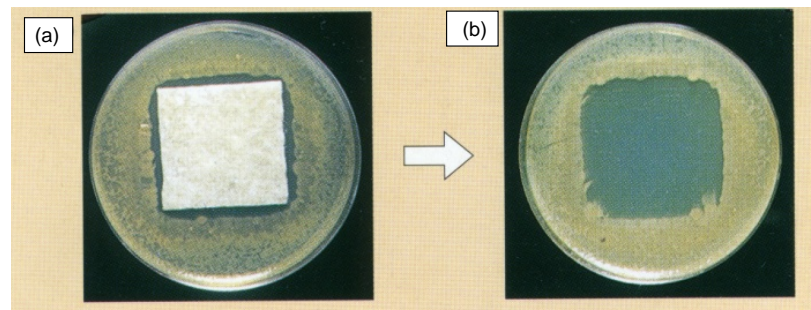

Figure 2. AgSD-wound dressing was placed on Pseudomonas aeruginosa-seeded agar for 3 days (a), then the wound dressing was removed (b), showing bactericidal effect.

intervals of 3 to 5 days until it adhered firmly to the wound. In cases of severe burns with necrotic skin, eschar and damaged tissue was removed by pharmaceutical or surgical debridement before application of this wound dressing. The wound dressing was exchanged at intervals of 3 to 5 days until it adhered firmly to the wound. When infection was present, the wound dressing was exchanged at intervals of 2 to 3 days until the wound surface became free from infection.

Of the 150 cases, including superficial second-degree burns, deep second-degree burns, third-degree burns, and third-degree decubitus, good or excellent results were achieved in more than $80 \%$ of all cases. For the treatment of deep second-degree burns, this wound dressing was stretched before application, making it possible to open the slits. The open-slit structure functioned to promote drainage and thus prevented excess accumulation of exudate beneath the wound dressing. For the treatment of superficial second-degree burns, this wound dressing was used without stretching, because in such cases a moist environment should be maintained. In practice, the closed-slit structure was adhered by coagulation of plasma proteins at an early stage after application, and thus functioned to provide the moist environment that had a beneficial effect on wound healing. Clinically, the drainage of exudate is very important in the management of severe burns where necrotic tissue is present, since accumulation of exudate, including biodegraded tissue debris, beneath the dressing is prone to lead to bacterial growth. 
Therefore, this wound dressing was designed to have slits to promote drainage of exudate. This slit structure was found to be critical in the successful management of severe burns. The size of the slits can be easily adjusted by stretching the dressing. In practice, this wound dressing is stretched when it is applied to severe burns, whereas it does not need to be stretched for the treatment of superficial second-degree burns.

\section{Development of Wound dressing Containing Growth Factor}

\subsection{Wound Dressing Composed of Hyaluronic Acid Sponge Containing Arginine and EGF}

The functional wound dressing composed of hyaluronic acid (HA) containing biological agents was developed [22]. HA has been identified as a major extracellular matrix component. HA is an essential biological material for wound healing, as it possesses various biological activities [23]. Because of its unique hygroscopic, rheologic and viscoelastic properties, HA creates an excellent wound healing environment. Moreover, it stimulates cell migration and angiogenesis [24]-[26]. It is generally accepted that the benefits of exogeneously applied HA lead to the development of tissue repair products [27] [28]. Arginine (Arg) has some unique biological properties. It has been demonstrated that an Arg-supplemented diet decreases tissue inflammatory cytokine expression and improves survival in burned rats [29]. Another report demonstrated that Arg is essential for T lymphocyte maturation [30]. In addition, Arg is a major substrate for the production of nitric oxide (NO), which is toxic to tumors and infected cells [31]. It has been reported that NO enhances collagen production and increases wound breaking strength [32]. These reports indicate that Arg and Arg-derived NO are useful for wound healing [33] [34].

EGF is beneficial in wound healing because of its effects on keratinocytes, fibroblasts and vascular endothelial cells, thus facilitating the formation of granulation tissue and epithelialization [35]-[38]. Excessive collagen formation is caused by aid of transforming growth factor (TGF)- $\beta 1$. This is one of the reasons for scar formation. Such an excessive collagen formation is reduced indirectly by the use of EGF, because EGF serves to decrease TGF- $\beta 1$ production. This efficacy suggests that EGF may be useful in antiscarring therapy [39]. Taking into account these properties of each ingredient, the novel wound dressings were desinged [40]. In order to evaluate the potential of EGF, two types of wound dressings were designed. Type I wound dressing is a spongy sheet composed of HA containing Arg. Type II wound dressing is a spongy sheet composed of HA containing Arg and EGF. Animal experiment using rats were conducted. Type II wound dressing more effectively facilitated epithelialization when compared with Type I. The release of EGF from the spongy sheet had a great contribution on epithelialization in the surgical wound.

\subsection{Wound Dressing Composed of Hyaluronic Acid and Collagen Sponge Containing EGF}

This functional wound dressing is the second version [41]-[43]. As described above, HA 
has a variety of functions to promote wound healing. In addition, collagen (Col) plays a pivotal role in wound healing; $\mathrm{Col}$ and Col-derived peptides act as a chemoattractant for fibroblasts in vitro and may have a similar activity in vivo [44]. Taking into account these properties of each ingredient, a spongy sheet composed of high molecular weight HA (HMW-HA), low molecular weight HA (LMW-HA) and Col containing EGF was desinged. Type I wound dressing is a spongy sheet composed of HMW-HA, LMW-HA, and cross-linked Col. Type II wound dressing is a spongy sheet composed of HMW-HA, LMW-HA, cross-linked Col containing EGF at $2 \mu \mathrm{g} / \mathrm{cm}^{2}$ (EGF-wound dressing).

The animal studie using rats was conducted. Under anesthesia, an area with a diameter of $3.5 \mathrm{~mm}$ in the abdominal region of rats was contacted with boiling water for 3 seconds in order to result in a third-degree burn. Necrotic skin was removed under anesthesia 3 days after burn injury. The wound area was covered with Type I or type II wound dressing. In control group the wound was covered with a commercially available alginate spongy wound dressing. Type I and type II wound dressings significantly promote the epithelialization when compared with the control group Figure 3. Particularly Type II wound dressing promoted epithelialization Figure 4. Treatment with either Type I or Type II wound dressing appeared to facilitate angiogenesis more effectively than in the control group. Particularly Type II wound dressing promoted angiogenesis.
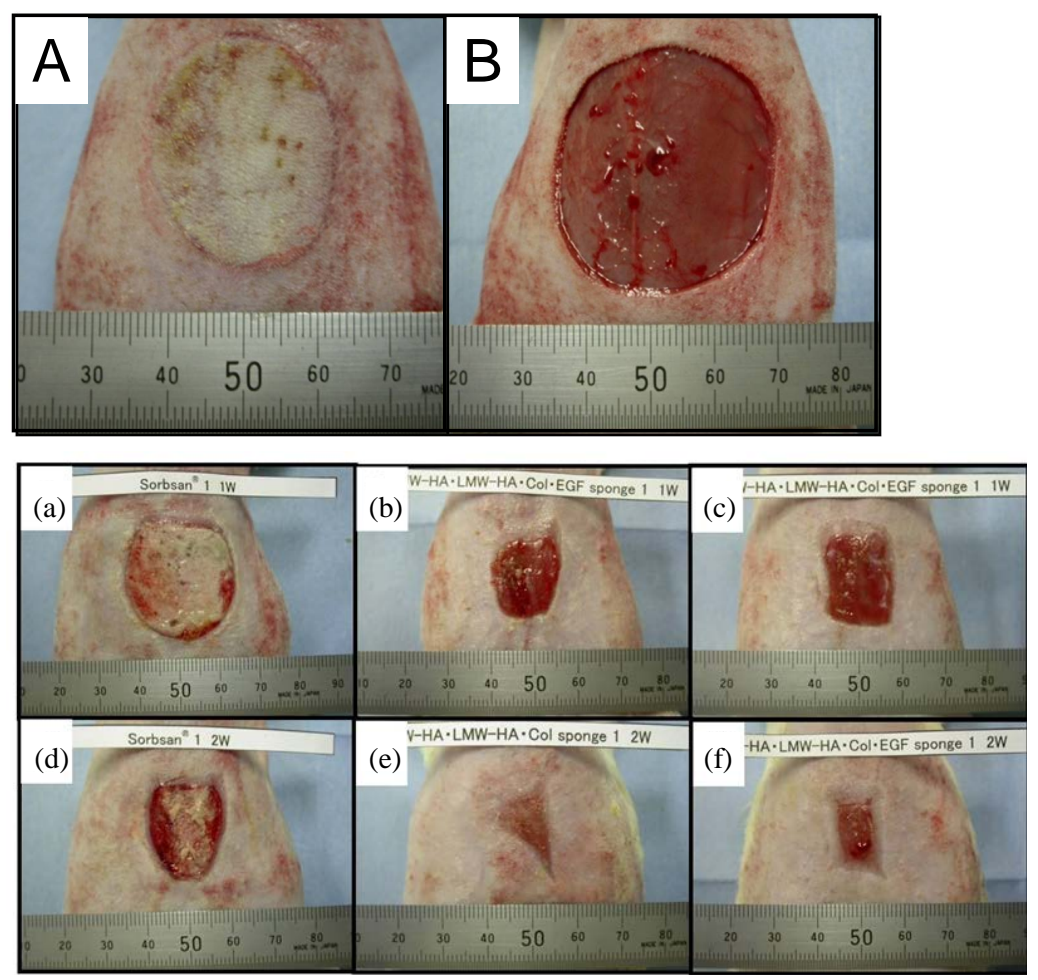

Figure 3. Burn wound surface after 3 days (A) and wound area after removal of necrotic skin (B). The wound surface after 1 week in (a) the control (alginate sponge), (b) Group I (HA/Col sponge), (c) Group II (EGF-HA/Col sponge), and after 2 weeks in (d) the control, (e) Group I, (f) Group II. 


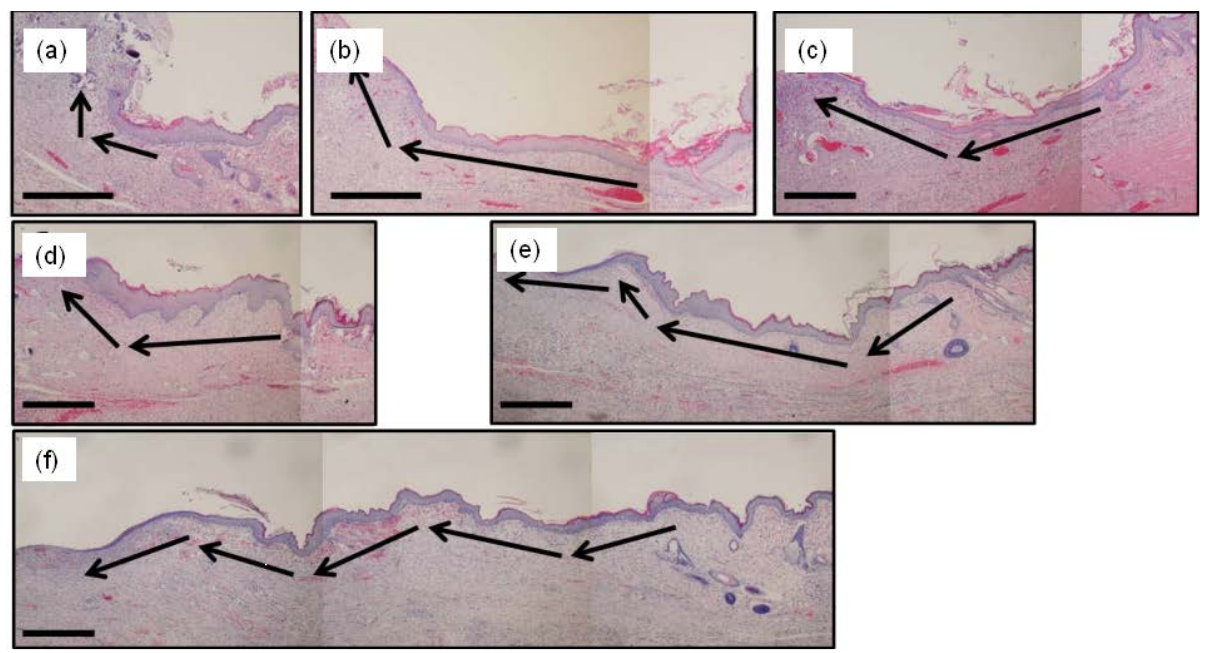

Figure 4. Histological appearances of the burn wound after 1 week in (a) the control (alginate sponge), (b) Group I (HA/Col sponge), (c) Group II (EGF-HA/Col sponge), after 2 weeks in (d) the control, (e) Group I, (f) Group II. Arrows indicate the distance of epithelialization from the wound margin. Scale bars $=500 \mu \mathrm{m}$.

On the basis of excellent results in the fundamental study, EGF-wound dressing was evaluated in 16 clinical cases, including deep second-degree burns, and third-degree burns, donor sites, traumatic skin defect, and intractable skin ulcers. Wound surfaces were debrided as necessary and rinsed with physiological saline solution. EGF-wound dressings were then applied to the wound site, on which a commercially available polyurethane film dressing was used as a top dressing. In the case of wounds associated with excess amounts of exudate, conventional ointment-gauze dressing was used as a top dressing. EGF-wound dressings were applied repeatedly at intervals of 3 to 5 days for a period of six weeks, or longer if necessary. For outcome, $93.7 \%$ of various wounds were evaluated as achieving good or excellent results. This EGF-wound dressing had proved quite effective for the management of a skin ulcer Figure 5.

Currently, several growth factor products are commercially available. Prior to clinical use, these products must be dissolved in the accompanying solution, preserved in a refrigerator and used within a specific time period. When aqueous solutions containing the growth factor are sprayed onto a wound site, a top dressing needs to be placed on the wound as a covering material. In addition, growth factor needs to be applied daily, as free growth factor dissolved in the accompanying solution has a short half-life at the wound site. This EGF-wound dressing can overcome the disadvantages associated with commercially available growth factor products.

\section{Development of Skin Care Product Containing Growth Factor}

\subsection{Skin Care Product Composed of Hyaluronic Acid Sponge Containing EGF and Cosmetic Ingredients}

Moving from the surface to the interior, there are five layers of the epidermis: horny layer, clear layer, granular layer, prickle cell layer, and basal layer. The two lowest cell 

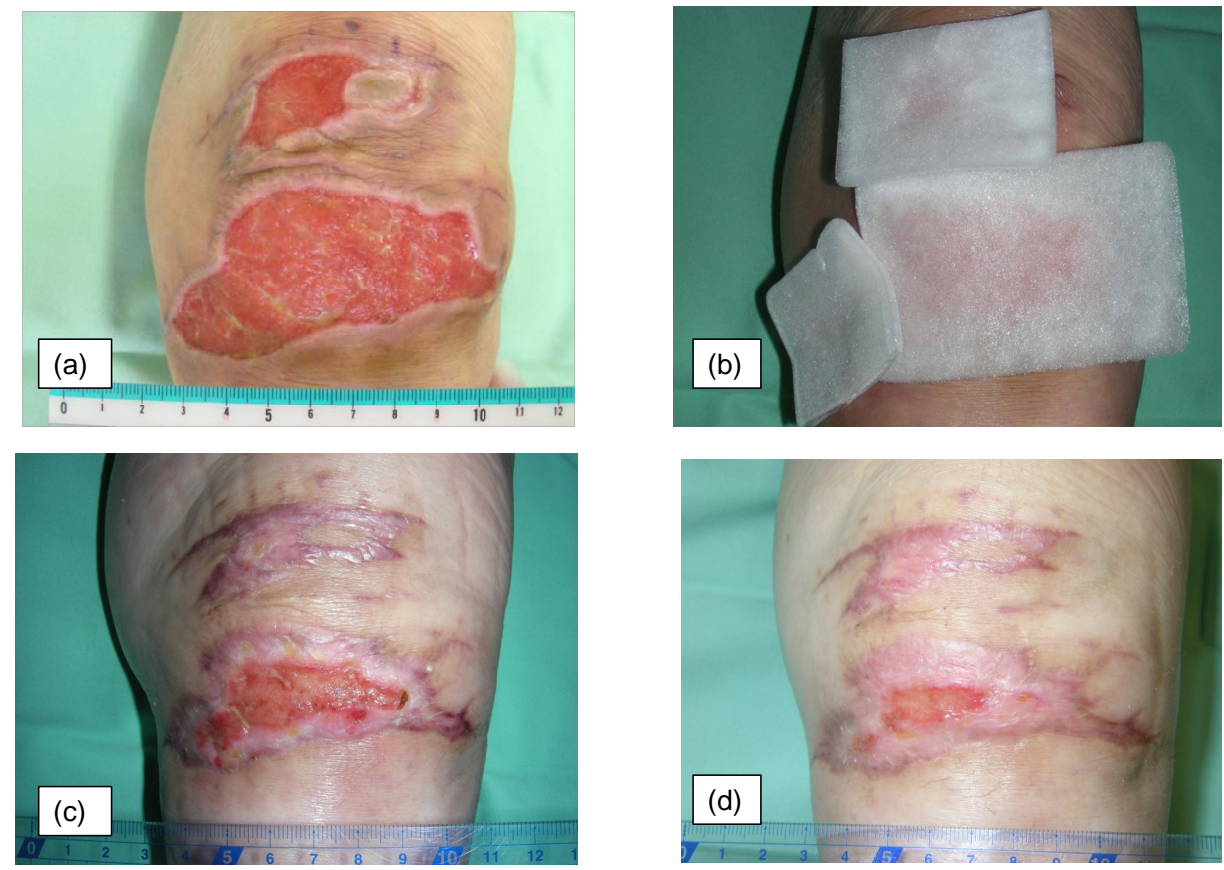

Figure 5. A 74-year-old woman who was developed a traumatic ulcer on the left knee: after 1 month-conventional therapy (a), EGF-wound dressing was applied every twice a week (b), and then wound size decreased significantly after 6 weeks (c) and 3 months (d).

layers consist of living cells that replenish the cells that are shed from the horny layer. The dermis is composed of two different regions: papillary dermis and reticular dermis. Fine vascular loops that provide nutrient supply to the epidermis are interspersed in the papillary dermis. The main cell in connective tissue is the fibroblast. Collagen fibers are interspersed in the reticular layer. Many different types of injury result in damage to the skin. However, the skin is capable of restoring the original protective covering by using repair mechanisms in the individual layers. Based on this regenerative potential of the skin, chemical peel using a chemical agent has been widely used in the field of aesthetic dermatology and aesthetic reconstructive surgery [45]-[48]. This procedure involves the application of a chemical agent that results in exfoliation of the skin followed by regrowth of new skin. This leads to skin rejuvenation. The treatment is classified into superficial, medium and deep peels. A superficial peel causes damage to the epidermis and the epidermal-dermal interface. A medium peel causes damage to the papillary dermis. A deep peel causes damage to the reticular dermis. Typical chemical agents are $10 \%-30 \%$ trichloroacetic acid (TCA) or $70 \%$ glycolic acid for superficial peels, $50 \%$ TCA for medium peels, and phenol or Baker-Gordon formula for deep peels. When strong acids come into contact with the skin, a deep corrosive wound result. The wound conditions vary depending on the concentration of the acid and the duration of exposure. Since this skin damage is due to the destruction of proteins, they resemble thermal burns. This type of injury is referred to as a superficial chemical burn.

Chemical peel can improve the skin condition when used properly but there is a risk of complications. Therefore, the benefit-to-risk ratio must be considered in the selection 
of the chemical peel. Although chemical peels result in chemical burns, most physicians did not focus on the importance of skin care products after chemical peels. In addition to choosing the appropriate peeling agent and their application period, the physician must choose the appropriate skin care product after chemical peels to obtain a satisfactory clinical result. The most critical issue is how to facilitate wound healing after chemical peels. Successful management of a corrosive wound caused by chemical peels requires the use of excellent skin care products that are capable of facilitating wound healing. This includes epithelialization, angiogenesis, and creation of a moist environment for re-epithelialization.

As described above, EGF is beneficial for wound healing because of its effects on proliferation of keratinocytes, fibroblasts and vascular endothelial cells, thus facilitating the formation of granulation tissue and re-epithelialization. In addition, EGF can stimulate fibroblasts to synthesize an increased amount of VEGF and HGF. VEGF and HGF are potent growth factors that promote angiogenesis. Recent research has demonstrated that simultaneous administration of VEGF and HGF synergistically promotes new blood vessel formation compared with administration of each factor alone [49]. In addition, HGF is considered to be one of the key cytokines involved in epithelialization in addition to angiogenesis [50]. Thus, EGF is a promising factor for wound healing. It is well known that $\mathrm{VC}$ is known to accelerate deposition of several basement membrane proteins, such as type IV and VII collagens at the dermal-epidermal junction [51]. VC has the potential for enhancing tissue repair [52]. In addition, VC has the potential to synergistically enhance HGF secretion by fibroblasts, when VC is applied together with growth factors such as EGF, PDGF and bFGF [53]. Thus the combination use of EGF and $\mathrm{VC}$ has a higher potential to stimulate fibroblasts to release increased amount of VEGF and HGF [54]. Therefore, VC is also a promising factor for wound healing. In addition, poly ( $\gamma$-glutamic acid) (PGA) and glucosylceramide (GC) have moisturizing effects in the epidermis. Based on the development of various types of wound dressing, a freeze-dried spongy sheet composed of HA and PGA, which contains various bioactive components including VC, GC, and EGF (skin care product with or without EGF) was developed [55]. Spongy sheets were categorized into the following groups: Group I (HA/PGA), Group II (HA/PGA + VC), Group III (HA/PGA + GC), Group IV (HA/PGA + VC, GC), Group V (HA/PGA + EGF), Group VI (HA/PGA + VC, EGF), Group VII (HA/PGA + GC, EGF), and Group VIII (HA/PGA + VC, GC, EGF).

The potential benefit of this skin care product was evaluated in animal experiments using nude mice. The dorsal region of nude mice was shaved under anesthesia and the left dorsal region was treated with gauze containing a certain amount of 50\% TCA. Specifically, this procedure involved contact with 50\% TCA-soaked gauze for $1 \mathrm{~min}$, followed by removal of the gauze, air exposure for $19 \mathrm{~min}$, and a rinse with sterilized DW. A piece of skin care product with EGF was placed onto this chemical burn area, and sterilized DW was added to hydrate the spongy sheet. A polyurethane film dressing was placed on the hydrated spongy sheet, on which gauze was placed and fixed with elastic tape. In the control group, the same procedure was performed without place- 
ment of any skin care product. This procedure was repeated at postoperative days 3, 7, and 10. The wound healing process was evaluated by examining the macroscopic appearance and histology at postoperative day 14 .

Figure 6 shows the macroscopic appearances of the wound caused by application of $50 \%$ TCA and the wound at postoperative day 14 . After 50\% TCA-soaked gauze was placed on the skin for $1 \mathrm{~min}$ followed by removal of the gauze, the wound initially showed a slightly whitish color. After exposure to air for $19 \mathrm{~min}$, the wound showed a distinct white color. The necrotic tissue caused by contact with TCA had formed a dry scab in the control group (no spongy sheet) at postoperative day 14. In contrast, in Group VIII, the majority of the scab had disappeared at postoperative day 14, and the wound condition was improved. Figure 7 shows the histological appearance of the wounds at postoperative day 14. The thickness of granulation tissue in four groups (Groups I, IV, V and VIII) was thicker than that in the control group. Granulation tissue formation with angiogenesis was facilitated in these four groups compared with the control group. The animal experiment results indicate that a spongy sheet composed of HA and PGA potentially enhances wound healing, and the incorporated VC, GC and EGF potentially increases the wound healing effect of the spongy sheet. The present animal experiment using 50\% TCA is categorized into deeper peels. Therefore, re-epithelialization was not completed within a two-week period.

\subsection{Skin Care Product Composed of Hyaluronic Acid and Collagen Sponge Containing EGF and Cosmetic Ingredients}

Base on the results related to the skin care product described above, another skin care product was developed [56]. This commercial available skin care product is composed of HA and Col containing EGF and VC, supplemented with GC, PGA, and Arg as cosmetic ingredients (EGF-skin care product). In order to demonstrate the efficacy of EGF, the amount of VEGF and HGF produced by fibroblasts were assessed in a wound surface model Figure 8. A fibroblast-incorporating Col gel sheet (cultured dermal substitute: CDS) was elevated to the air-medium interface, onto which a spongy sheet of EGF-skin care product was placed (+EGF) and cultured for 7 days. In control groups, no EGF-skin care product was placed (-EGF). The amount of VEGF was measured in order to evaluate the efficacy of EGF. Fibroblasts in the CDS released 3.7-times more VEGF in (+) EGF compared with (-) EGF Figure 9. This finding demonstrates that EGF-skin care product effectively stimulated fibroblast to synthesize an increased amount of VEGF. In addition to this, the amount of HGF was measured. Fibroblasts released 25-times more HGF in (+) EGF compared with (-) EGF Figure 10. This finding demonstrates that EGF-skin care product more effectively stimulated fibroblast to synthesize an increased amount of HGF. It is noteworthy that HGF production was significantly higher than VEGF production. These findings suggest that EGF-skin care product can be used on damaged skin surface. The enhancement of keratinocyte proliferation is essential for the treatment of superficial wound. In addition, the enhancement of fibroblasts proliferation and vascularization is essential for the treatment of 

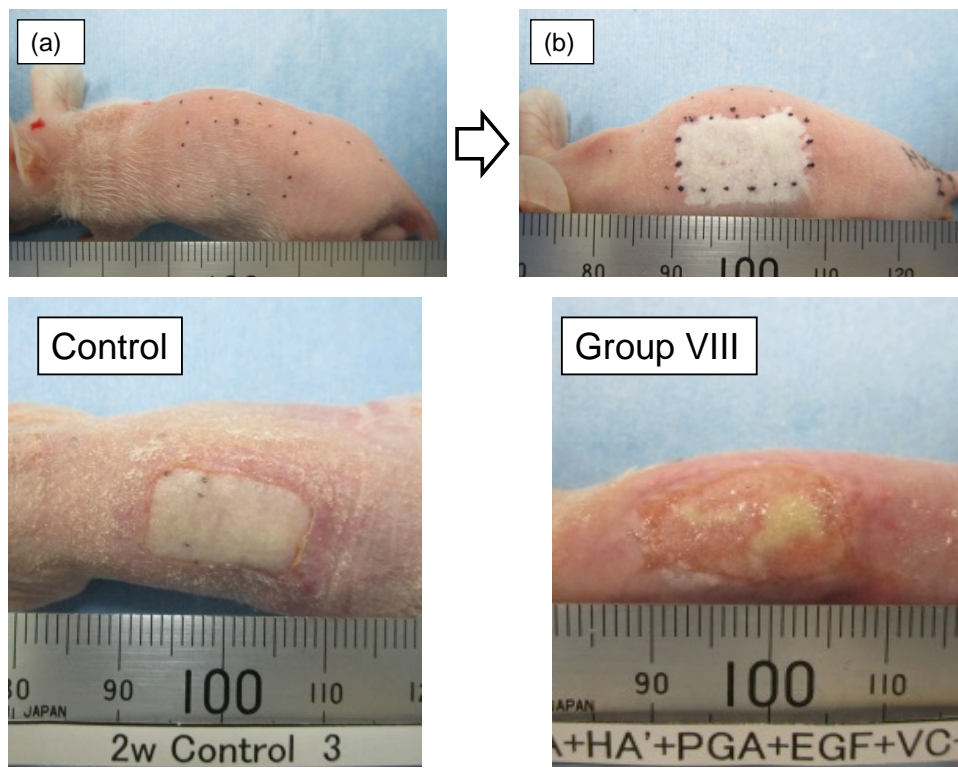

Figure 6. Macroscopic appearances of before (a) and after (b) chemical peeling using 50\% TCA. The wound surface at 2 weeks in the control group without sponge and Group VIII .

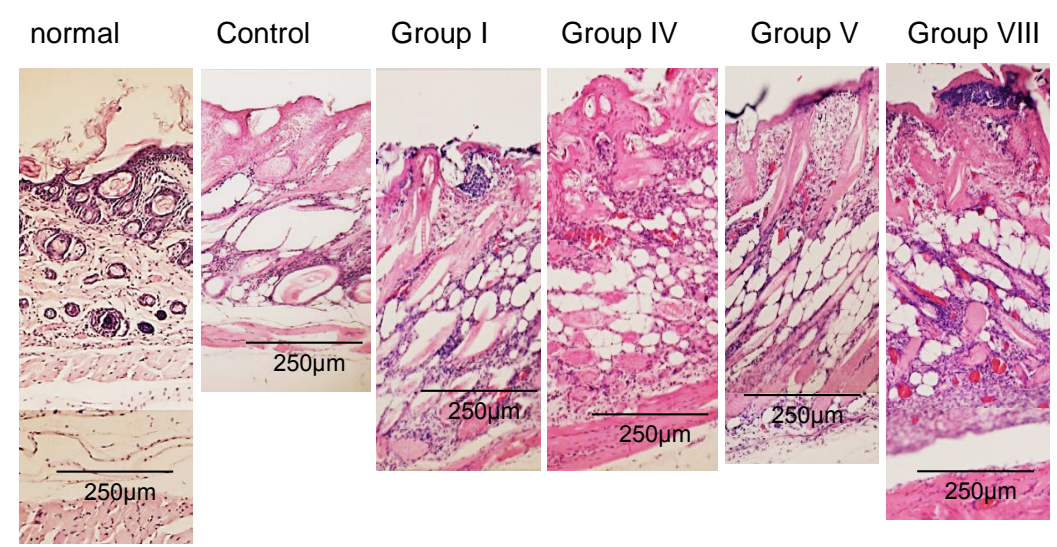

Figure 7. Histological appearances of the dermis after chemical peeling at 2 weeks in the control, Group I, Group IV, Group V, Group VIII, and the normal skin.
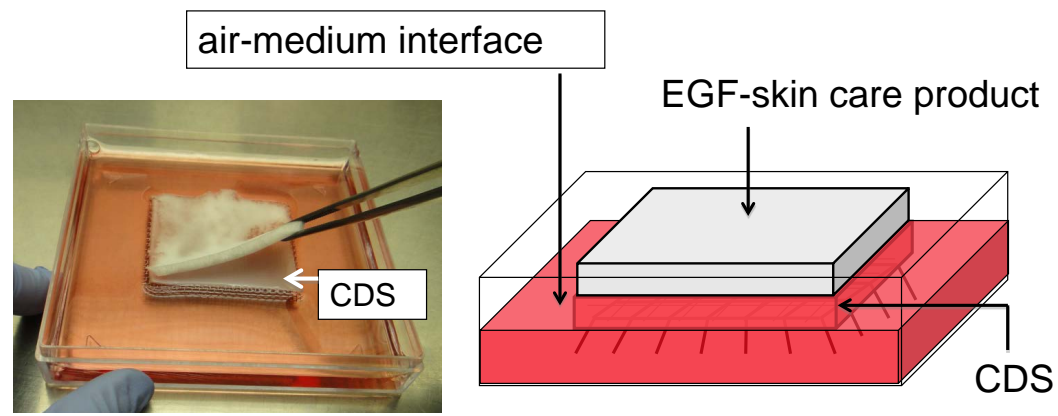

Figure 8. Measurement of cytokine production: a sheet of EGF-skin care product is placed on CDS elevated to the air-medium interface (wound surface model). 


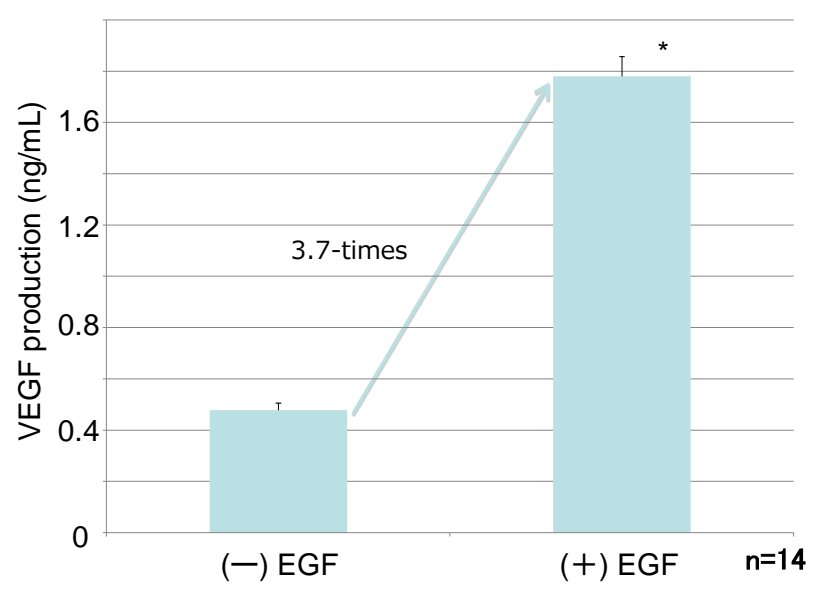

Figure 9. Results on quantitative analysis of VEGF production by fibroblasts in CDS covered with or without EGF-skin care product. ${ }^{*} \mathrm{p}<0.01$ vs. ( $\left.\mathrm{EGF}\right)$.

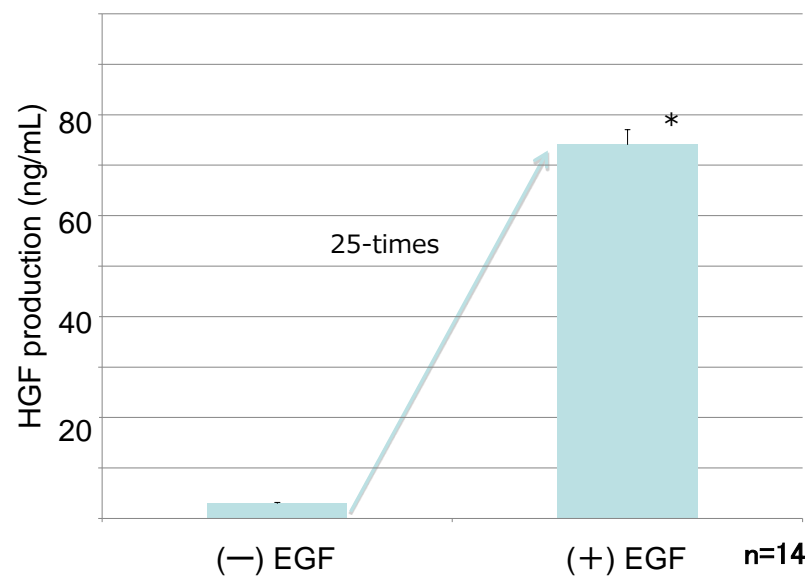

Figure 10. Results on quantitative analysis of HGF production by fibroblasts in CDS covered with or without EGF-skin care product. ${ }^{*} \mathrm{p}<0.01$ vs. $(-\mathrm{EGF})$.

deeper wound. The application of EGF is promising, because the EGF has both functions to enhance the keratinocyte and fibroblasts proliferation and also stimulate fibroblasts to release vascularization factors.

\section{Tissue Engineering for Skin Regenerative Medicine}

\subsection{Development of Various Types of Tissue-Engineered Product Using Cells}

Regenerating medicine is based on the tissue engineering. In general, the tissue-engineered products include three prime constituents, i.e., cells, growth factors, and materials (often referred to as scaffold). In the first approach, the growth factor is incorporated into biodegradable materials, followed by transplanting into a site of damaged tissues. The growth factor allows the patient's own cells to migrate into the desired area 
and regenerate the lost tissue. In the second approach, the procedure entails the proliferation of isolated cells from own tissue or a donor's tissue. These cells are seeded on or within a scaffold such as biodegradable materials. As well as delivering the cells, the scaffold both creates and maintains a space for the formation of new tissue. In this approach, the patient receives autologous cells that have been harvested previously and proliferated. The entire structure of autologous cells combined with a scaffold is transplanted into the lost area of tissue, where the cells proliferate and form new tissue. According to this technique, allogeneic cells also can be combined with a scaffold. Although allogeneic cells are rejected gradually in immune system, they are able to release some types of growth factors, and thereby regenerate a damaged tissue.

According to the second approach, a number of skin substitutes with autologous or allogeneic cells have been produced by some culture techniques. Cultured epidermal substitute (CES) is composed of stratified keratinocytes. Cultured dermal substitute (CDS) is composed of fibroblasts combined with a scaffold. Cultured skin substitute (CSS) is composed of fibroblasts combined with a scaffold bearing stratified keratinocytes. There are two categories depending on the origin of the cell; autologous cells or allogeneic cells.

The pioneering work of Green and co-workers has demonstrated that it is possible to grow keratinocytes as a stratified sheet from a single cell suspension in the system using 3T3 feeder layer [57] [58]. The resulting multilayered epithelial sheet has proved very effective in the management of skin defect [59]-[61]. Autologous CES has been evaluated in many hospitals and proved very effective [62]-[64]. On the other hand, Bell and co-workers developed CSS composed of a collagen gel sheet containing fibroblast whose outer surface was combined with a stratified layer of keratinocytes [65] [66]. Allogeneic CSS has been evaluated in many hospitals and proved very effective [67]. Hansbrough and co-workers developed CDS composed of a biodegradable synthetic polymer mesh, polyglactin-910, combined with allogeneic cultured fibroblasts [68]. Kuroyanagi and co-workers developed an autologous CSS that was prepared through the successive cultivation of autologous fibroblasts and keratinocytes that were placed on each surface of a collagen spongy sheet [69]. According to this technique, allogeneic CDS composed of a collagen spongy sheet containing allogeneic fibroblsts was developed [70]-[72].

Some types of tissue-engineered products, allogeneic CSS and allogeneic CDS, have been commercialized as excellent biological dressings. These products are composed of cultured keratinocytes and/or fibroblasts. Immunological response is generally linked to the presence of class II MHC (major histocompatibility complex) antigen on the surface of cell. Although macrophages, lymphocytes, Langerhans cells, and endothelial cells express class II MHC antigens, keratinocytes and fibroblasts express class I MHC antigens. The cells used in allogeneic CES, CDS and CSS, therefore, express class I MHC antigen, but do not constitutively express class II MHC antigens. In clinical cases after cultivation and cell selection, neither keratinocytes nor fibroblasts trigger a substantial allogeneic response [73]. These tissue-engineered products are expected to faci- 
litate tissue repair in burn and ulcer wounds, because incorporated cultured keratinocytes and fibroblasts can release a lot of biologically active substances that are necessary for wound healing.

\subsection{Establishment of Banking System for Allogeneic CDS}

Cell banking was established by the procedure described in the article [74]. A small piece of skin was obtained from patients younger than one year-old during surgical excision of excrescence. This patient was free from infectious viruses such as HBV, HCV, HIV and HTLV, and also negative on the treponema pallidum hemagglutination test (TPHA). Fibroblasts isolated by enzymatic treatment were cultivated successively in culture medium to establish cell banking. The cultured fibroblasts were suspended in a cryopreserved medium (DMEM supplemented with 10\% DMSO and 20\% FBS). This cell suspension was poured in a cryo-tube, and then cryopreserved at $-152^{\circ} \mathrm{C}$ according to a conventional procedure.

The CDS was prepared using a method described in the article [75] [76]. The fibroblasts obtained from successive cultivation of the cryopreserved cells were seeded onto the 2-layered sponge by adding cellular suspension dropwise onto the collagen surface of the sponge. The number of fibroblasts on the 2-layered sponge was adjusted to $1.0 \times$ $10^{5} \mathrm{cells} / \mathrm{cm}^{2}$. The cell-seeded sponge was kept in an incubator in a humidified atmosphere of $5 \% \mathrm{CO}_{2}$ at $37^{\circ} \mathrm{C}$ overnight, followed by adding cultured medium and culturing for 1 week Figure 11. The fibroblasts used in production of CDS were checked for mycoplasma and confirmed to be negative. The culture medium used in production of CDS was checked for bacteria and confirmed to be negative. Cryopreservation and thawing of CDS was performed according to the method described in the articles [77] [78]. We measured the amounts of 8 cytokines: VEGF, bFGF, HGF, PDGF-AA, TGF- $\beta 1$, KGF, IL-6 and IL-8 [79] [80]. The results demonstrate that the cryopreserved CDS can release VEGF, bFGF, HGF, TGF- $\beta 1$ and IL- 8 at appreciable levels.
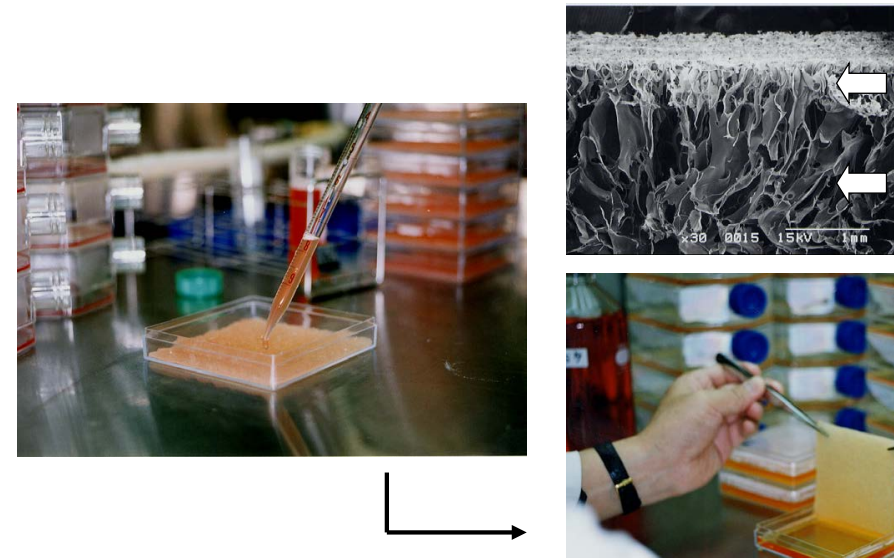

\section{Col sponge}

HA sponge

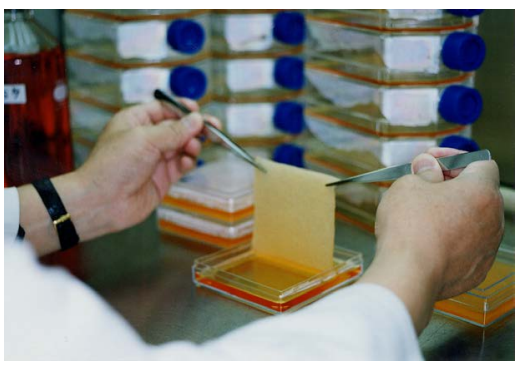

Figure 11. CDS prepared by seeding and culturing fibroblasts on a two-layered sponge composed of hyaluronic acid (HA) and collagen (Col). 
A multi-center clinical study of this allogeneic CDS conducted at 31 hospitals across Japan began in April 2000 and concluded in March 2005, as part of the Regenerating Medical Millennium Projects of the Ministry of Health, Labor and Welfare. For this clinical study, 4700 sheets of CDS were prepared at the R \& D Center for Artificial Skin, School of Allied Health Sciences, Kitasato University, and were delivered to the participating hospitals. The clinical study has been conducted in compliance with the ethical guidelines of the participating hospitals. Clinical results have been obtained for 404 cases, including severe burns and intractable skin ulcers. Excellent results was obtained in $62.6 \%$, good results was obtained in $30.0 \%$, fair results was obtained in $6.7 \%$, and poor results was obtained in $0.7 \%$ of the cases Figure 12 . Some of these results have been reported in the articles [81]-[88]. The representative clinical results are shown. A 95-year-old woman who developed an intractable skin ulcer was treated with allogeneic CDS. The wound condition had successfully improved 1 month later. The skin ulcer had healed after 2 months Figure 13. A 90-year-old woman who developed squamous cell carcinoma was treated with allogeneic CDS. CDS was applied to the debrided wound surface. The wound condition improved dramatically, and the debrided wound surface had healed completely after 28 days Figure 14. An 88-year-old woman who developed necrotizing fasciitis was treated with a 6-fold extended mesh split-thickness auto-skin graft and allogeneic CDS. In this case, the graft was applied and then covered with the CDS. The extended mesh graft had taken successfully after 28 days, and showed excellent epithelialization despite poor wound conditions Figure 15.

\section{Conclusion}

The artificial skins are divided into two categories: wound dressing and cultured skin substitute. Wound healing process sometimes fails to proceed under the impaired conditions such as burn injury and intractable skin ulcer. To improve these wound conditions, researchers have been trying to create several types of artificial skins. In this review, the material designs of three types of tissue-engineered products are introduced. These designs are based on the concept of wound healing mechanism. A major ob

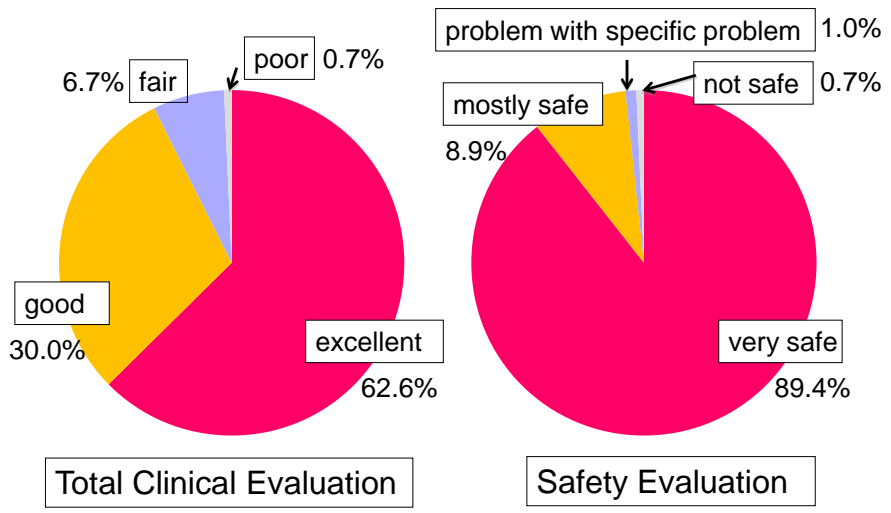

Figure 12. Total clinical evaluation and safety evaluation on 415 clinical cases. 

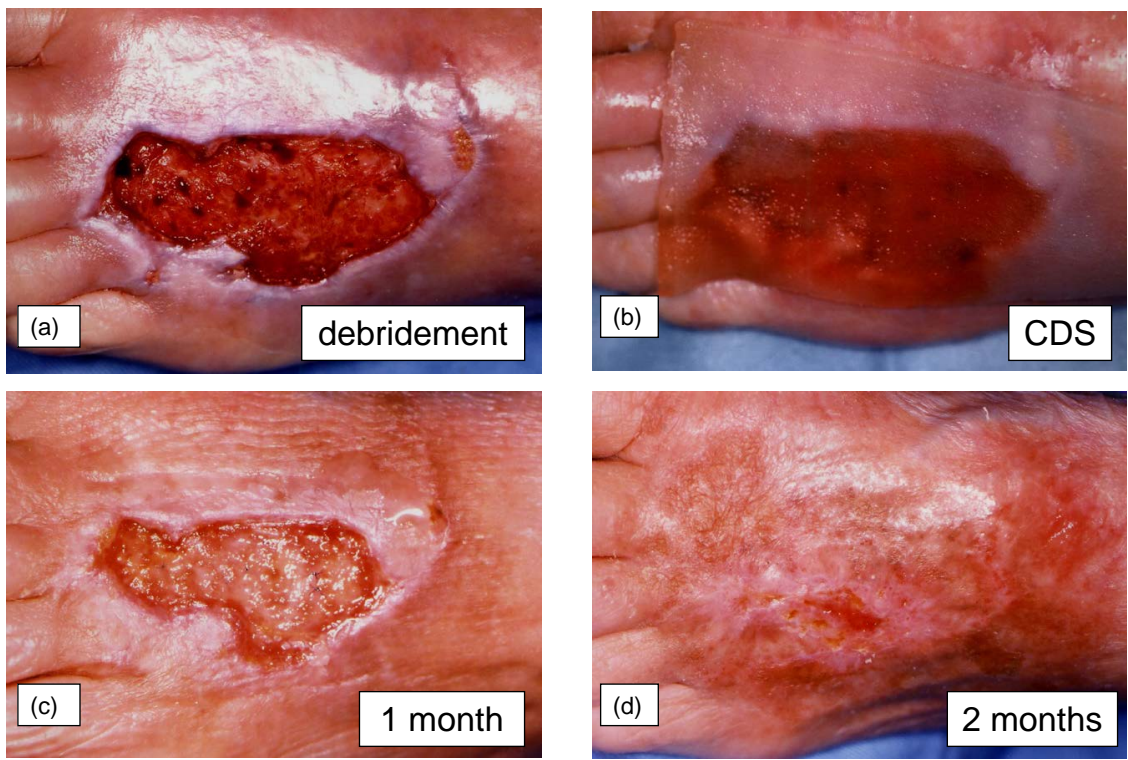

Figure 13. A 95-year-old woman developed an intractable skin ulcer: the part of skin ulcer was debrided (a), on which CDS was applied repeatedly at an interval of 5 to 7 days, and the debrided wound was improved (c), and then healed after 2 months (d).
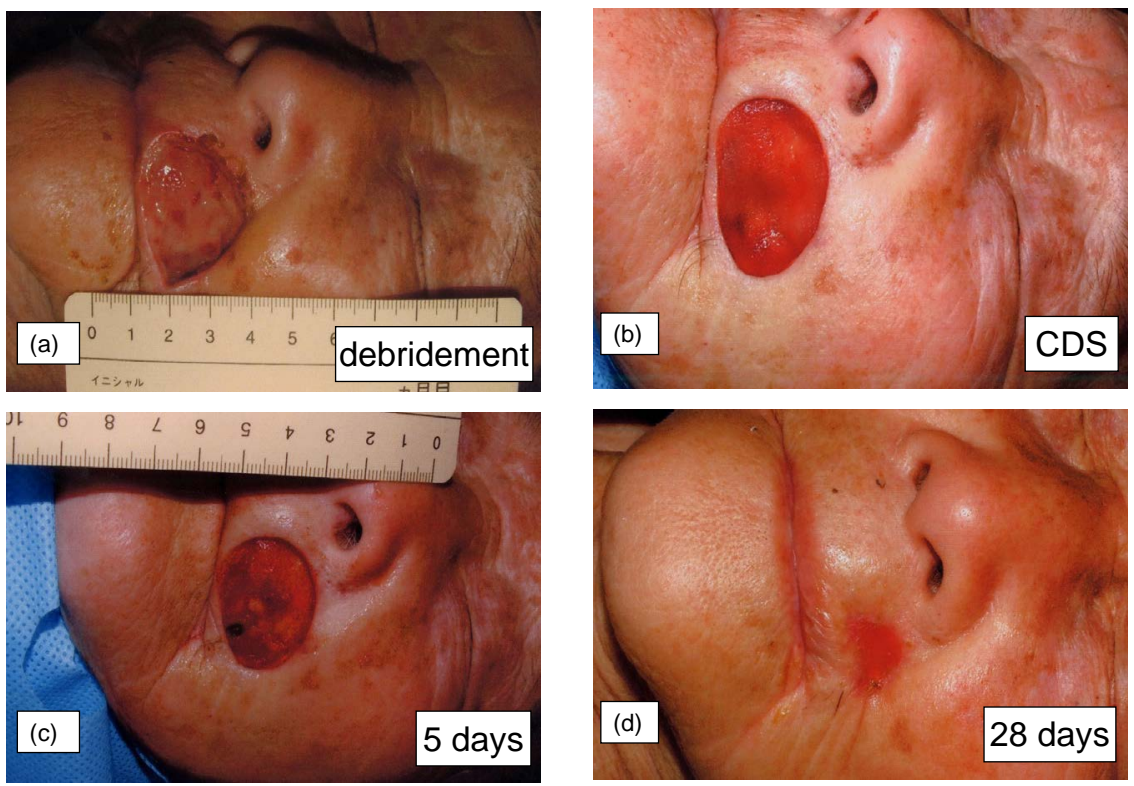

Figure 14. A 90-year-old woman developed squamous cell carcinoma: the part of carcinoma was debrided, on which CDS was applied repeatedly at an interval of 5 to 7 days, and the debrided wound was improved (c), and then healed after 28 days (d).

struction to wound healing is infection. Another obstruction to wound healing is deficiency of growth factors. The critical issue is to remove these obstructions and to provide an excellent environment for wound healing. The author developed functional wound dressings containing antimicrobial agent or growth factor, and cultured dermal substitute capable of releasing several types of growth factors. The clinical study demon 

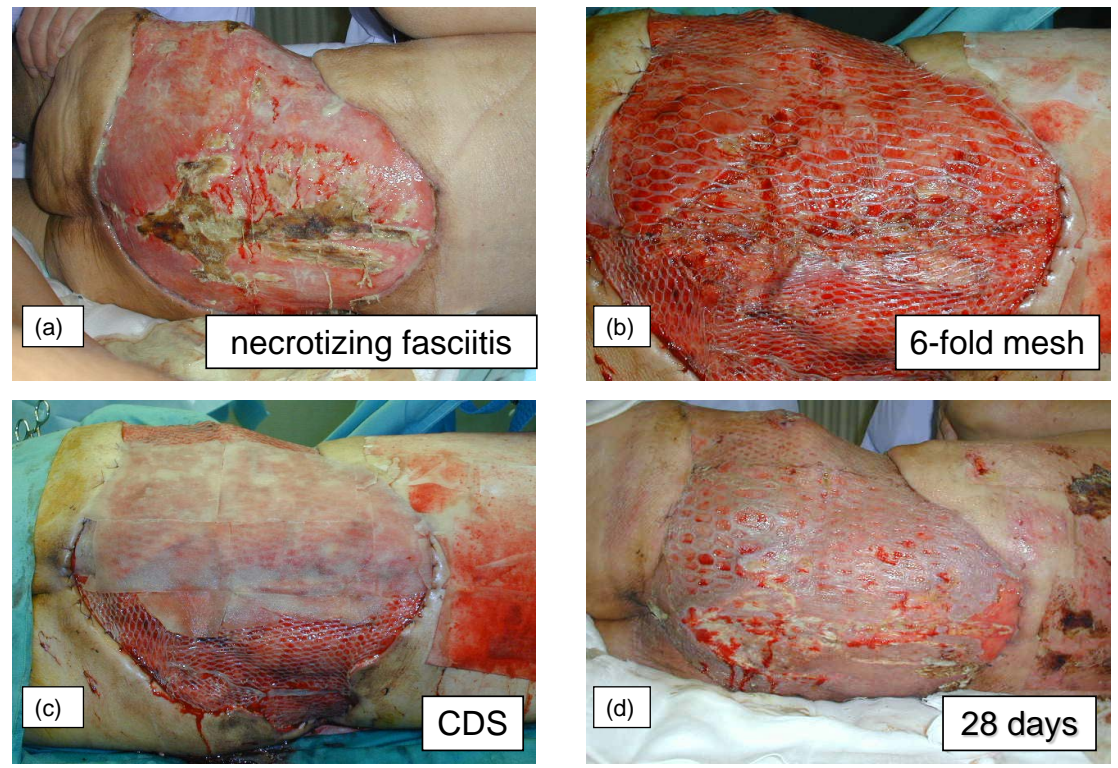

Figure 15. An 88-year-old woman developed necrotizing fasciitis (a): the part of fasciitis was debrided, on which 6-fold extended mesh split-thickness auto-skin was grafted (b), on which CDS was applied repeatedly at an interval of 5 to 7 days (c), and then the graft showed an excellent condition after 28 days (d).

strates that these tissue-engineered products are promising for the treatment of burn injury and intractable skin ulcer.

\section{Acknowledgements}

The author has no conflict of interest associated with this manuscript.

\section{References}

[1] Clark, R.A.F. (1985) Cutaneous Tissue Repair: Basic Biological Considerations. I. Journal of the American Academy of Dermatology, 13, 701-725.

http://dx.doi.org/10.1016/S0190-9622(85)70213-7

[2] LeGrand, E.X. (1998) Preclinical Promise of Becaplemin (rhPDGF-BB) in Wound Healing. The American Journal of Surgery, 176, 48S-54S.

http://dx.doi.org/10.1016/S0002-9610(98)00177-9

[3] Robson, M.C., Phillips, L.G., Lawrence, W.T., Bishop, J.B., Youngerman, J.S., Hayward, P.G., Broemeling, L.D. and Heggers, J.P. (1992) The Safety and Effect of Topically Applied Recombinant Basic Fibroblast Growth Factor on Healing of Chronic Pressure Sores. Annals of Surgery, 216, 401-408. http://dx.doi.org/10.1097/00000658-199210000-00002

[4] Falanga, V., Eaglstein, W.H., Bucalo, B., Kartz, M.H., Harris, B. and Carson, P. (1992) Topical Use of Human Recombinat Epidermal Growth Factor (h-EGF) in Venous Ulcers. The Journal of Dermatologic Surgery and Oncology, 18, 604-606. http://dx.doi.org/10.1111/j.1524-4725.1992.tb03514.x

[5] Corral, C.J., Siddiqui, A., Wu, L., Farrell, C.L., Lyons, D. and Mustoe, T.A. (1999) Vascular Endothelial Growth Factor Is More Important than Basic Fibroblastic Growth Factor during Ischemic Wound Healing. Archives of Surgery, 134, 200-205.

http://dx.doi.org/10.1001/archsurg.134.2.200 
[6] Nayeri, F., Stromberg, T., Larsson, M., Brudin, L., Soderstrom, C. and Forsberg, P. (2002) Hepatocyte Growth Factor May Accelerate Healing in Chronic Leg Ulcers: A Pilot Study. Journal of Dermatological Treatment, 13, 81-86. http://dx.doi.org/10.1080/095466302317584449

[7] Winter, G.D. (1962) Formation of the Scab and the Rate of Epithelization of Superficial Wounds in the Skin of the Young Domestic Pig. Nature, 193, 293-294. http://dx.doi.org/10.1038/193293a0

[8] Heimbach, D.M. (1987) Early Burn Excision and Grafting. Surgical Clinics of North America, 67, 93-107. http://dx.doi.org/10.1016/S0039-6109(16)44135-6

[9] Tompkins, R.G., Remensnyder, J.P., Burke, J.F., Tomkins, D.M., Hilton, J.F., Schoenfeld, D.A., Behringer, G.E., Bondoc, C.C., Briggs, S.E. and Quinby, W.C. (1988) Significant Reductions in Mortality for Children with Burn Injuries through the Use of Prompt Eschar Excition. Annals of Surgery, 208, 577-585. http://dx.doi.org/10.1097/00000658-198811000-00006

[10] Herndon, D.N., Barrow, R.E., Rutan, R.L., Rutan, T.C., Desai, M.H. and Abston, S.Y. (1989) A Comparison of Conservative versus Early Excision Therapy in Severely Burned Patients. Annals of Surgery, 209, 547-553. http://dx.doi.org/10.1097/00000658-198905000-00006

[11] Tavis, M.J., Thornton, J.W., Bartlett, R.H., Roth, J.C. and Woodroof, E.A. (1980) A New Composite Skin Prosthesis. Burns, 7, 123-130. http://dx.doi.org/10.1016/0305-4179(80)90038-8

[12] Burke, J.F., Yannas, I.V., Quinby, W.C., Bondoc, C.C. and Jung, W.K. (1981) Successful Use of a Physiologically Acceptable Artificial Skin in the Treatment of Extensive Burn Injury. Annals of Surgery, 194, 413-428. http://dx.doi.org/10.1097/00000658-198110000-00005

[13] Yannas, I.V., Burke, J.F., Orgill, D.P. and Skrabut, E.M. (1982) Wound Tissue Can Utilize a Polymeric Template to Synthesize a Functional Extension of Skin. Science, 215, 174-176. http://dx.doi.org/10.1126/science.7031899

[14] Suzuki, S., Matsuda, K., Isshiki, N., Tamada, Y., Yoshioka, K. and Ikada, Y. (1990) Clinical Evaluation of a New Bilayer Artificial Skin Composed of Collagen Sponge and Silicone Layer. British Journal of Plastic Surgery, 43, 47-54. http://dx.doi.org/10.1016/0007-1226(90)90044-Z

[15] Koide, M., Osaki, K., Konishi, J., Oyamada, K., Katakura, T., Takahashi, A. and Yoshizato, K. (1993) A New Type of Biomaterial for Artificial Skin: Dehydrothermally Cross-Linked Composites of Fibrillar and Denatured Collagen. Journal of Biomedical Materials Research, 27, 79-87. http://dx.doi.org/10.1002/jbm.820270111

[16] Kuroyanagi, Y., Kim, E. and Shioya, N. (1990) Evaluation of Synthetic Wound Dressing Capable of Releasing Silver Sulfadiazine. Journal of Burn Care \& Rehabilitation, 11, 106115.

[17] Kuroyanagi, Y., Kim, E., Kenmochi, M., Ui, K., Kageyama, H., Nakamura, M., Takeda, A. and Shioya, N. (1992) A Silver Sulfadiazine Impregnated Synthetic Wound Dressing Composed of Poly-L-Leucine Spongy Matrix. Journal of Applied Biomaterials, 3, 153-161. http://dx.doi.org/10.1002/jab.770030211

[18] Matsuda, K., Suzuki, S., Isshiki, N., Yoshioka, K., Okada, T., Hyon, S.H. and Ikada, Y. (1991) A Bilayer "Artificial Skin" Capable of Sustained Release of an Antibiotic. British Journal of Plastic Surgery, 44, 142-146. http://dx.doi.org/10.1016/0007-1226(91)90049-P

[19] Kuroyanagi, Y., Shiraishi, A., Shirasaki, Y., Nakakita, N., Yasutomi, Y., Takano, Y. and Shioya, N. (1994) Development of New Wound Dressing with Antimicrobial Delivery Capability. Wound Repair and Regeneration, 2, 122-129. 
http://dx.doi.org/10.1046/j.1524-475X.1994.20206.x

[20] Kuroyanagi, Y., Kageyama, H., Shioya, N., Ohara, A. and Mikawa, T. (1995) Development of New Wound Dressing Composed of Silver Sulfadiazine-Impregnated Polyurethane Membrane Laminated with a Non-Woven Fabric; Fundamental Studies. Japan Pharmacology \& Therapeutics, 23, 25-35.

[21] Kuroyanagi, Y., Shioya, N., Nakakita, N., Nakamura, M., Takahashi, H., Yasutomi, Y., Ishihara, S., Kim, E., Kageyama, H., Matsukura, T., Sato, A., Nakajima, H., Anze, M., Ikezawa, Z., Moori, S., Ichiyama, S., Kageyama, M., Hara, H., Wada, H., Okano, E. and Ogino, K. (1995) Development of New Wound Dressing Composed of Silver Sulfadiazine-Impregnated Polyurethane Membrane Laminated with a Non-Woven Fabric; Multi-Center's Clinical Reports. Japan Pharmacology \& Therapeutics, 23, 383-408.

[22] Matsumoto, Y. and Kuroyanagi, Y. (2010) Development of Wound Dressing Composed of Hyaluronic Acid Sponge Containing Epidermal Growth Factor. Journal of Biomaterials Science, 21, 715-726. http://dx.doi.org/10.1163/156856209X435844

[23] Laurent, T.C. and Fraser, J.R. (1992) Hyaluronan. FASEB Journal, 6, 2397-2404.

[24] West, D.C., Hampson, I.N., Arnold, F. and Kumar, S. (1985) Angiogenesis Induced by Degradation Products of Hyaluronic Acid. Science, 228, 1324-1326. http://dx.doi.org/10.1126/science.2408340

[25] Sattar, A., Rooney, P., Kumar, S., Pye, D., West, D.C., Scott, I. and Ledger, P. (1994) Application of Angiogenic Oligosaccharides of Hyaluronan Increases Blood Vessel Numbers in Rat Skin. Journal of Investigative Dermatology, 103, 576-579.

[26] Lees, V.C., Fan, T.P. and West, D.C. (1995) Angiogenesis in a Delayed Revascularization Model Is Accelerated by Angiogenic Oligosaccharides of Hyaluronan. Lab. Invest, 73, 259-266.

[27] Chen, W.Y.J. and Abatangelo, G. (1999) Functions of Hyaluronan in Wound Repair. Wound Repair and Regeneration, 7, 79-89. http://dx.doi.org/10.1046/j.1524-475X.1999.00079.x

[28] Pardue, E.L., Ibrahim, S. and Ramamurthi, A. (2008) Role of Hyaluronan in Angiogenesis and Its Utility to Angiogenic Tissue Engineering. Organogenesis, 4, 203-214. http://dx.doi.org/10.4161/org.4.4.6926

[29] Cui, X.L., Iwasa, M., Iwasa, Y. and Ogoshi, S. (2000) Arginine-Supplemented Diet Decreases Expression of Inflammatory Cytokines and Improves Survival in Burned Rats. Journal of Parenteral \& Enteral Nutrition, 24, 89-96. http://dx.doi.org/10.1177/014860710002400289

[30] Ochoa, J.B., Strange, J., Kearney, P., Gellin, G., Endean, E. and Fitzpatrick, E. (2001) Effects of L-Arginine on the Proliferation of T Lymphocyte Subpopulations. Journal of Parenteral \& Enteral Nutrition, 25, 23-29. http://dx.doi.org/10.1177/014860710102500123

[31] Kirs, S.J. and Barbul, A. (1990) Role of Arginine in Trauma, Sepsis, and Immunity. Journal of Parenteral \& Enteral Nutrition, 14, 226S-229S. http://dx.doi.org/10.1177/014860719001400514

[32] Zhu, H., Ka, B. and Murad, F. (2007) Nitric Oxide Accelerates the Recovery from Burn Wounds. World Journal of Surgery, 31, 624-631. http://dx.doi.org/10.1007/s00268-007-0727-3

[33] Witte, M.B. and Barbul, A. (2003) Arginine Physiology and Its Implication for Wound Healing. Wound Repair and Regeneration, 11, 419-423. http://dx.doi.org/10.1046/j.1524-475X.2003.11605.x

[34] Curran, J.N., Winter, D.C. and Bouchier-Hayes, D. (2006) Biological Fate and Clinical Implications of Arginine Metabolism in Tissue Healing. Wound Repair and Regeneration, 14, 
376-386. http://dx.doi.org/10.1111/j.1743-6109.2006.00151.x

[35] Carpenter, G. and Cohen, S. (1976) Human Epidermal Growth Factor and the Proliferation of Human Fibroblasts. Journal of Cellular Physiology, 88, 227-237. http://dx.doi.org/10.1002/jcp.1040880212

[36] Carpenter, G. and Cohen, S. (1979) Epidermal Growth Factor. Annual Review of Biochemistry, 48, 193-216. http://dx.doi.org/10.1146/annurev.bi.48.070179.001205

[37] Hong, J.P., Kim, Y.W., Jung, H.D. and Jung, K.I. (2006) The Effect of Various Concentrations of Human Recombinant Epidermal Growth Factor on Split Thickness Skin Wounds. International Wound Journal, 3, 123-132. http://dx.doi.org/10.1111/j.1742-4801.2006.00187.x

[38] Lee, A.R. (2005) Enhancing Dermal Matrix Regeneration and Biomechanical Properties of $2^{\text {nd }}$ Degree-Burn Wounds by EGF-Impregnated Collagen Sponge Dressing. Archives of Pharmacal Research, 28, 1311-1316. http://dx.doi.org/10.1007/BF02978217

[39] Park, J.S., Kim, J.Y., Cho, J.Y., Kang, J.S. and Yu, Y.H. (2000) Epidermal Growth Factor (EGF) Antagonizes Transforming Growth Factor (TGF)-Beta 1-Induced Collagen Lattice Contraction by Human Skin Fibroblasts. Biological and Pharmaceutical Bulletin, 23, 15211523.

[40] Matsumoto, Y., Arai, K., Momose, H. and Kuroyanagi, Y. (2009) Development of Wound Dressing Composed of Hyaluronic Acid Sponge Containing Arginine. Journal of Biomaterials Science, 20, 993-1004. http://dx.doi.org/10.1163/156856209X444394

[41] Kondo, S. and Kuroyanagi, Y. (2012) Development of Wound Dressing Composed of Hyaluronic Acid and Collagen Sponge with Epidermal Growth Factor. Journal of Biomaterials Science, 23, 629-643. http://dx.doi.org/10.1163/092050611X555687

[42] Kondo, S., Niiyama, H., Yu, A. and Kuroyanagi, Y. (2012) Evaluation of a Wound Dressing Composed of Hyaluronic Acid and Collagen Sponge Containing Epidermal Growth Factor in Diabetic Mice. Journal of Biomaterials Science, 23, 1729-1740.

[43] Yu, A., Matsuda, Y., Takeda, A., Uchinuma, E. and Kuroyaangi, Y. (2012) Effect of EGF and bFGF on Fibroblast Proliferation and Angiogenic Cytokine Production from Cultured Dermal Substitutes. Journal of Biomaterials Science, 23, 1315-1324.

[44] Postlethwaite, A.E., Seyer, J.M. and Kang, A.H. (1978) Chemotactic Attraction of Human Fibroblasts to Type I, II, and III Collagens and Collagen-Derived Peptides. Proceedings of the National Academy of Sciences of the United States of America, 78, 871-875. http://dx.doi.org/10.1073/pnas.75.2.871

[45] Wolfort, F.G., Dalton, W.E. and Hoopes, J.E. (1972) Chemical Peel with Trichloracetic Acid. British Journal of Plastic Surgery, 25, 333-334. http://dx.doi.org/10.1016/S0007-1226(72)80071-7

[46] Coleman III, W.P. and Brody, H.J. (1997) Advances in Chemical Peeling. Dermatologic Clinics, 15, 19-26. http://dx.doi.org/10.1016/S0733-8635(05)70411-3

[47] Dinner, M.I. and Artz, J.S. (1998) The Art of the Trichloroacetic Acid Chemical Peel. Clinics in Plastic Surgery, 25, 53-62.

[48] Brody, H.J., Monheit, G.D., Resnik, S.S. and Alt, T.H. (2000) A History of Chemical Peeling. Dermatologic Surgery, 26, 405-409. http://dx.doi.org/10.1046/j.1524-4725.2000.00505.x

[49] Xin, X., Yang, S., Ingle, G., Zlot, C., Rangell, L., Kowalski, J., Schwall, R., Ferrara, N. and Gerritsen, M.E. (2001) Hepatocyte Growth Factor Enhances Vascular Endothelial Growth Factor-Induce Angiogenesis in Vitro and in Vivo. The American Journal of Pathology, 158, 1111-1120. http://dx.doi.org/10.1016/S0002-9440(10)64058-8 
[50] Conway, K., Price, P., Harding, K.G. and Jiang, W.G. (2006) The Molecular and Clinical Impact of Hepatocyte Growth Factor, Its Receptor, Activators, and Inhibitors in Wound Healing. Wound Repair and Regeneration, 14, 2-10.

http://dx.doi.org/10.1111/j.1524-475x.2005.00081.x

[51] Marionnet, C., Vioux-Chagnoleau, C., Pierrard, C., Sok, J., Asselineau, D. and Bernerd, F. (2006) Morphogenesis of Dermal-Epidermal Junction in a Model of Reconstracted Skin: Beneficial Effects of Vitamin C. Experimental Dermatology, 15, 625-633. http://dx.doi.org/10.1111/j.1600-0625.2006.00454.x

[52] Lima, C.C., Pereira, A.P.C., Silva, J.R.F., Oliveira, L.S., Resck, M.C.C., Grechi, C.O., Bernardes, M.T.C.P., Olimpio, F.M.P., Santos, A.M.M., Lncerpi, E.K. and Garcia, J.A.D. (2009) Ascorbic Acid for the Healing of Skin Wounds in Rats. Brazilian Journal of Biology, 69, 1195-1201. http://dx.doi.org/10.1590/S1519-69842009000500026

[53] Wu, Y.L., Gohda, E., Iwao, M., Matsunaga, T., Nagao, T., Takebe, T. and Yamamoto, I. (1998) Stimulation of Hepatocyte Growth Factor Production by Ascorbic Acid and Its Stable 2-Glucoside. Growth Hormone and IGF Research, 8, 421-428. http://dx.doi.org/10.1016/S1096-6374(98)80313-4

[54] Niiyama, H. and Kuroyanagi, Y. (2014) Development of Novel Wound Dressing Composed of Hyaluronic Acid and Collagen Sponge Containing Epidermal Growth Factor and Vitamin C Derivative. Journal of Artificial Organs, 17, 81-87. http://dx.doi.org/10.1007/s10047-013-0737-x

[55] Isago, Y., Suzuki, R., Isono, E., Noguchi, Y. and Kuroyanagi, Y. (2014) Development of a Freeze-Dried Skin Care Product Composed of Hyaluronic Acid and Poly ( $\gamma$-Glutamic Acid) Containing Bioactive Components for Application after Chemical Peels. Open Journal of Regenerative Medicine, 3, 43-53. http://dx.doi.org/10.4236/ojrm.2014.33006

[56] Yamamoto, A., Ohno, H. and Kuroyanagi, Y. (2016) Evaluation of Epidermal Growth Factor-Incorporating Skin Care Product in Culture Experiment Using Human Fibroblasts. Open Journal of Regenerative Medicine, 5, 44-54. http://dx.doi.org/10.4236/ojrm.2016.52004

[57] Rheinwald, J.G. and Green, H. (1977) Epidermal Growth Factor and the Multiplication of Cultured Human Epidermal Keratinocytes. Nature, 265, 421-424. http://dx.doi.org/10.1038/265421a0

[58] Green, H., Kehinde, O. and Thomas, J. (1979) Growth of Cultured Human Epidermal Cells into Multiple Epithelia Suitable for Grafting. Proceedings of the National Academy of Sciences of the United States of America, 76, 5665-5668. http://dx.doi.org/10.1073/pnas.76.11.5665

[59] O'Connor, N.E., Muliken, J.G., Banks-Schlegel, S., Keinde, O. and Green, H. (1982) Grafting of Burns with Cultured Epithelium Prepared from Autologous Epidermal Cells. The Lancet, 317, 75-78. http://dx.doi.org/10.1016/S0140-6736(81)90006-4

[60] Gallico, G.G., O’Connor, N.E., Compton, C.C., Kehinde, O. and Green, H. (1984) Permanent Coverage of Large Burn Wounds with Autologous Cultured Human Epithelium. The New England Journal of Medicine, 311, 448-451. http://dx.doi.org/10.1056/NEJM198408163110706

[61] Cuono, C.B., Langdon, R. and McGuire, J. (1986) Use of Cultured Epidermal Autografts and Dermal Allografts as Skin Replacement after Burn Injury. The Lancet, 327, 1123-1124. http://dx.doi.org/10.1016/S0140-6736(86)91838-6

[62] Compton, C.C., Gill, J.M., Bradford, D.A., Regauer, S., Gallico, G.G. and O’Connor, N.E. (1989) Skin Regenerated from Cultured Epithelial Autografts on Full-Thickness Burn Wounds from 6 Days to 5 Years after Grafting. Laboratory Investigation, 60, 600-612. 
[63] Odessey, R. (1992) Addendum: Multicenter Experience with Cultured Epidermal Autograft for Treatment of Burns. Journal of Burn Care \& Rehabilitation, 13, 174-180. http://dx.doi.org/10.1097/00004630-199201000-00038

[64] Rue, L.W., Cioffi, W.C., McManus, W.F. and Pruitt, B.A. (1993) Wound Closure and Outcome in Extensively Burned Patients Treated with Cultured Autologous Keratinocytes. Journal of Trauma-Injury Infection \& Critical Care, 34, 662-668.

http://dx.doi.org/10.1097/00005373-199305000-00008

[65] Bell, E., Ehrlich, H.P., Buttle, D.J. and Nakatsuji, T. (1981) Living Tissue Formed in Vitro and Accepted as Skin-Equivalent Tissue of Full Thickness. Science, 211, 1052-1054. http://dx.doi.org/10.1126/science.7008197

[66] Bell, E., Ehrlich, H.P., Sher, S., Merrill, C., Sarber, R., Hull, B., Nakatsuji, T. and Church, D. (1981) Development and Use of a Living Skin Equivalent. Plastic \& Reconstructive Surgery, 67, 386-392. http://dx.doi.org/10.1097/00006534-198103000-00024

[67] Parenteau, N. (1999) Skin: The First Tissue-Engineered Products. Scientific American, 280, 83-84.

[68] Hansbrough, J.F., Christine, D. and Hansbrough, W.B. (1992) Clinical Trials of a Living Dermal Tissue Replacement Placed beneath Meshed, Split-Thickness Skin Graft on Excised Burn Wounds. Journal of Burn Care \& Rehabilitation, 13, 519-529. http://dx.doi.org/10.1097/00004630-199209000-00004

[69] Kuroyanagi, Y., Kenmochi, M., Ishihara, S., Takeda, A., Shiraishi, A., Ootaka, N., Uchinuma, E., Torikai, K. and Shioya, N. (1993) A Cultured Skin Substitute Composed of Fibroblasts and Keratinocytes with a Collagen Matrix: Preliminary Results of Clinical Trials. Annals of Plastic Surgery, 31, 340-349. http://dx.doi.org/10.1097/00000637-199310000-00011

[70] Yamashita, R., Kuroyanagi, Y., Nakakita, N., Uchinuma, E. and Shioya, N. (1999) Allogeneic Cultured Dermal Substitute Composed of Spongy Collagen Containing Fibroblasts: Preliminary Clinical Trials. Wounds, 11, 34-44.

[71] Yamada, N., Uchinuma, E. and Kuroyanagi, Y. (1999) Clinical Evaluation of an Allogeneic Cultured Dermal Substitute Composed of Fibroblasts within a Spongy Collagen Matrix. Scandinavian Journal of Plastic and Reconstructive Surgery and Hand Surgery, 33, 147-154. http://dx.doi.org/10.1080/02844319950159398

[72] Kuroyanagi, Y., Yamada, N., Yamashita, R. and Uchinuma, E. (2001) Tissue-Engineered Product: Allogeneic Cultured Dermal Substitute Composed of Spongy Collagen with Fibroblasts. Artificial Organs, 25, 180-186. http://dx.doi.org/10.1046/j.1525-1594.2001.025003180.x

[73] Bell, E. and Rosenberg, M. (1990) The Commercial Use of Cultivated Human Cells. Transplantation Proceedings, 22, 971-974.

[74] Kuroyanagi, Y., Kubo, K., Matsui, H., Kim, H.J., Numari, S., Mabuchi, Y. and Kagawa, S. (2004) Establishment of Banking System for Allogeneic Cultured Dermal Substitute. Artificial Organs, 28, 13-21. http://dx.doi.org/10.1111/j.1525-1594.2004.07318.x

[75] Kubo, K. and Kuroyanagi, Y. (2003) Characterization of a Cultured Dermal Substitute Composed of a Spongy Matrix of Hyaluronic Acid and Collagen Combined with Fibroblasts. Journal of Artificial Organs, 6, 138-144.

[76] Kubo, K. and Kuroyanagi, Y. (2003) Effects of Vascular Endothelial Growth Factor Released from Cultured Dermal Substitute on Proliferation of Vascular Endothelial Cells in Vitro. Journal of Artificial Organs, 6, 267-272. http://dx.doi.org/10.1007/s10047-003-0239-3

[77] Kubo, K. and Kuroyanagi, Y. (2004) Development of a Cultured Dermal Substitute Composed of a Spongy Matrix of Hyaluronic Acid and Atelo-Collagen Combined with Fibrob- 
lasts: Cryopreservation. Artificial Organs, 28, 182-188.

http://dx.doi.org/10.1111/j.1525-1594.2004.47219.x

[78] Kubo, K. and Kuroyanagi, Y. (2005) The Possibility of Long-Term Cryopreservation of Cultured Dermal Substitute. Artificial Organs, 29, 800-805.

http://dx.doi.org/10.1111/j.1525-1594.2005.00132.x

[79] Kubo, K. and Kuroyanagi, Y. (2005) A Study of Cytokines Released from Fibroblasts in Cultured Dermal Substitute. Artificial Organs, 29, 845-849.

http://dx.doi.org/10.1111/j.1525-1594.2005.00138.x

[80] Hashimoto, A. and Kuroyanagi, Y. (2008) Standardization for Mass Production of Allogeneic Cultured Dermal Substitute by Measuring the Amount of VEGF, bFGF, HGF, TGF- $\beta$, and IL-8. Journal of Artificial Organs, 11, 225-231. http://dx.doi.org/10.1007/s10047-008-0436-1

[81] Kashiwa, N., Ito, O., Ueda, T., Kubo, K., Matsui, H. and Kuroyanagi, Y. (2004) Treatment of Full-Thickness Skin Defect with Concomitant Grafting of 6-Fold Extended Mesh Auto-Skin and Allogeneic Cultured Dermal Substitute. Artificial Organs, 28, 444-450. http://dx.doi.org/10.1111/j.1525-1594.2004.00009.x

[82] Ohtani, T., Okamoto, K., Kaminaka, C., Kishi, T., Sakurane, M., Yamamoto, Y., Ueda, K., Kubo, K., Kuroyanagi, Y. and Furukawa, F. (2004) Digital Gangrene Associated with Idiopathic Hypereosinophilia: Treatment with Allogeneic Cultured Dermal Substitute (CDS). European Journal of Dermatology, 14, 168-171.

[83] Moroi, Y., Fujita, S., Fukagawa, S., Mashino, T., Goto, T., Masuda, T., Urabe, K., Kubo, K., Matsui, H., Kagawa, S., Kuroyanagi, Y. and Furue, M. (2004) Clinical Evaluation of Allogeneic Cultured Dermal Substitutes for Intractable Skin Ulcers after Tumor Resection. European Journal of Dermatology, 14, 172-176.

[84] Hasegawa, T., Suga, Y., Mizoguchi, M., Muramatsu, S., Mizuno, Y., Haruna, K., Ikeda, S., Kuroyanagi, Y. and Ogawa, H. (2007) Intractable Venous Leg Ulcer Treated Successfully with Allogeneic Cultured Dermal Substitute. Scandinavian Journal of Plastic and Reconstructive Surgery and Hand Surgery, 41, 326-328. http://dx.doi.org/10.1080/02844310600723224

[85] Yamada, N., Uchinuma, E. and Kuroyanagi, Y. (2008) Clinical Trial of Allogeneic Cultured Dermal Substitute for Intractable Skin Ulcers of the Lower Leg. Journal of Artificial Organs, 11, 100-103. http://dx.doi.org/10.1007/s10047-008-0406-7

[86] Ohara, N., Mihara, S., Nihara, H., Akimoto, N., Madokoro, N., Kawai, M., Noda, H., Hide, M., Matsumoto, Y. and Kuroyanagi, Y. (2010) A Case of Lower-Extremity Deep Burn Wounds with Periosteal Necrosis Successfully Treated by Use of Allogeneic Cultured Dermal Substitute. Journal of Artificial Organs, 13, 101-105.

http://dx.doi.org/10.1007/s10047-010-0499-7

[87] Taniguchi, T., Amoh, Y., Katsuoka, K. and Kuroyanagi, Y. (2012) Treatment of Intractable Skin Ulcers by Vascular Insufficiency with Allogeneic Cultured Dermal Substitute: A Report of 8 Cases. Journal of Artificial Organs, 15, 77-82. http://dx.doi.org/10.1007/s10047-011-0601-9

[88] Yamada, N., Uchinuma, E. and Kuroyanagi, Y. (2012) Clinical Trial of Allogeneic Cultured Dermal Substitutes for Intractable Skin Ulcers. Journal of Artificial Organs, 15, 193-199. http://dx.doi.org/10.1007/s10047-011-0618-0 
Submit or recommend next manuscript to SCIRP and we will provide best service for you:

Accepting pre-submission inquiries through Email, Facebook, LinkedIn, Twitter, etc. A wide selection of journals (inclusive of 9 subjects, more than 200 journals)

Providing 24-hour high-quality service

User-friendly online submission system

Fair and swift peer-review system

Efficient typesetting and proofreading procedure

Display of the result of downloads and visits, as well as the number of cited articles

Maximum dissemination of your research work

Submit your manuscript at: http://papersubmission.scirp.org/

Or contact ojrm@scirp.org 